\title{
Role of Sodium in Thyroid Hormone Uptake by Rat Skeletal Muscle
}

\author{
M. Centanni and J. Robbins \\ Clinical Endocrinology Branch, National Institute of Diabetes and Digestive and Kidney Diseases, \\ National Institutes of Health, Bethesda, Maryland 20892
}

\begin{abstract}
Whether $\mathrm{Na}^{+}$movement through the plasma membrane plays a role in thyroid hormone uptake was investigated in intact rat soleus muscles. After preincubation for $120 \mathrm{~min}$ at $37^{\circ} \mathrm{C}$ in modified Krebs-Ringer bicarbonate containing 140 or $5 \mathrm{mM}$ $\mathrm{Na}^{+}$plus choline or lithium to maintain osmolarity, muscles were incubated with $50 \mathrm{pM}\left[{ }^{125} \mathrm{I}\right]$ triiodo-L-thyronine $\left(\mathrm{T}_{3}\right)$ or [ $\left.{ }^{125} I\right] L$-thyroxine $\left(T_{4}\right)$ for $60 \mathrm{~min}$. $T_{3}$ uptake was decreased when extracellular $\mathrm{Na}^{+}$was replaced by either choline or lithium, the amount of decrease corresponding to the specific (or saturable) uptake component. Monensin, an ionophore that stimulates $\mathrm{Na}^{+}$entry, increased $\mathrm{T}_{3}$ uptake at $140 \mathrm{mM} \mathrm{Na}{ }^{+}$but not at $5 \mathrm{mM} \mathrm{Na}^{+}$. Amiloride, a $\mathrm{Na}^{+} / \mathrm{H}^{+}$exchange inhibitor, had no effect on $\mathrm{T}_{3}$ uptake under basal conditions or when $\mathrm{Na}^{+}$ was replaced by choline, but reversed the action of lithium. Ouabain, an inhibitor of $\mathrm{Na}^{+} / \mathrm{K}^{+}$ATPase, reduced specific $\mathrm{T}_{3}$ uptake. $\mathrm{T}_{4}$ uptake was unaffected by low extracellular $\mathrm{Na}^{+}$. These results are consistent with a major role of $\mathrm{Na}^{+}$movement in $T_{3}$ uptake by skeletal muscle, but not in $T_{4}$ uptake, and suggest an involvement of membrane pumps in this process.
\end{abstract}

\section{Introduction}

The possible role of the plasma membrane in regulating peripheral thyroid hormone metabolism has been extensively studied (1-9). A specific hormone uptake has been described in hepatocytes (6), erythrocytes (5), lymphocytes (4), pituicytes (8), and fibroblasts (9). Previous studies in our laboratory demonstrated that part of the 3,5,3'-triiodo-L-thyronine $\left(\mathrm{T}_{3}\right)^{1}$ entering skeletal muscle cells does so by a stereo-specific and energy- and temperature-dependent process (10). In this tissue the nuclear-associated $T_{3}$ derives almost exclusively from circulating $T_{3}$ (11) without contribution from the intracellular 5 -deoidination of thyroxine $\left(\mathrm{T}_{4}\right)$, thus indicating that the plasma membrane might modulate the availability of active thyroid hormone. However, the exact mechanism of thyroid hormone entry into cells is still poorly defined.

A role of sodium in thyroid hormone uptake was suggested in hepatocytes by Krenning et al. (6) and in erythrocytes by

Dr. Centanni's present address is II Cattedra di Endocrinologia, c/o II Clinica Medica Universita "La Sapienza," Policinico Umberto I, 00186, Roma, Italy. Address all correspondence and requests to Dr. J. Robbins, Bldg. 10, Rm. 8N315, National Institutes of Health, Bethesda, MD 20892.

Received for publication 25 August 1986 and in revised form 24 April 1987.

1. Abbreviations used in this paper: $\mathrm{KRB}, \mathrm{Krebs}-\mathrm{Ringer}$ bicarbonate; $\mathrm{pH}_{\mathrm{i}}$, internal $\mathrm{pH} ; \mathrm{T}_{3}, 3,5,3^{\prime}$-triiodo-L-thyronine; $\mathrm{T}_{4}$, thyroxine.

The Journal of Clinical Investigation, Inc.

Volume 80, October 1987, 1068-1072
Holm et al. (5) based on ouabain sensitivity of the initial rate of uptake by these tissues. Sodium plays a major role in amino acid transport across the cell membrane, and the " $A$ " system, mediating the concentrative uptake of neutral amino acids, is strictly sodium dependent $(12,13)$. Thyroid hormone is an amino acid derivative, although apparently not sharing the A system (unpublished data). The aim of the present study was to investigate the relation between sodium movement across the plasma membrane and thyroid hormone entry into rat soleus muscle.

\section{Methods}

L-T $\mathrm{T}_{3}, \mathrm{~L}-\mathrm{T}_{4}$, amiloride, and monensin were purchased from Sigma Chemical Co. (St. Louis, MO). Ouabain was obtained from Calbiochem-Behring Corp. (La Jolla, CA). [ $\left.{ }^{125} \mathrm{I}\right] \mathrm{L}-\mathrm{T}_{3}(3,300 \mu \mathrm{Ci} / \mu \mathrm{g})$ and $\left[{ }^{125} \mathrm{I}\right] \mathrm{L}-\mathrm{T}_{4}(4,400 \mu \mathrm{Ci} / \mu \mathrm{g})$ were purchased from New England Nuclear (Boston, MA). The purity of labeled and unlabeled hormones was assayed by thin-layer chromatography on silica gel K1F (Whatman, Inc., Clifton, NJ) using the solvent system formic acid/methanol/chloroform (1:3:16), according to Sato and Cahnmann (14).

Sprague-Dawley male rats weighing 70-130 g were purchased from Taconic Farms, Inc. (Germantown, NY). The animals were kept for at least $3 \mathrm{~d}$ before the experiment, had free access to commercial food pellets (Ziegler Brothers, Inc., Gardners, PA) and water, and were maintained at constant temperature with a light-dark cycle of $12 \mathrm{~h}$. Rats were killed by carbon dioxide inhalation and soleus muscles were excised as previously described (15) and placed in ice-cold buffer for $\sim 30$ min. Modified Krebs-Ringer bicarbonate (KRB) buffer, containing $5 \mathrm{mM}$ sodium pyruvate and half the usual $\mathrm{CaCl}_{2}$ concentration (i.e., $2.5 \mathrm{mM}$ ), was used throughout the study; in low sodium experiments, $\mathrm{Na}^{+}$was replaced by equimolar amounts of choline; when lithium was used, it replaced sodium chloride up to a final concentration of $120 \mathrm{mM}$ lithium and choline $\mathrm{HCO}_{3}^{-}$was substituted for $\mathrm{NaHCO}_{3}$. In both cases the buffer contained $5 \mathrm{mM}$ sodium due to the presence of $\mathrm{Na}^{+}$pyruvate as an energy source.

To perform uptake studies the isolated muscles were preincubated for $120 \mathrm{~min}$ at $37^{\circ} \mathrm{C}, \mathrm{pH} \mathrm{7.38}$, in capped borosilicate vials containing $\mathrm{KRB}$ under an atmosphere of $\mathrm{O}_{2} / \mathrm{CO}_{2}(95: 5 \%)$ in a shaking water bath (40 oscillations/min). Incubation was carried out after addition of 50 $\mathrm{pM}\left[{ }^{125} \mathrm{I}\right] \mathrm{T}_{3}$ or $\left[{ }^{125} \mathrm{I}\right] \mathrm{T}_{4}$ for 60 min unless otherwise specified. Unlabeled thyroid hormone was added, where appropriate, only during incubation; all the other substances were present during both preincubation and incubation. The final $\mathrm{pH}$ did not exceed 7.55; experiments with larger $\mathrm{pH}$ variations were discarded. The incubation was ended by rinsing the muscles in ice-cold buffer; the muscles were then blotted on filter paper, and tendons were accurately removed. The total radioactivity in each vial was measured before the incubation, and the radioactivity incorporated during incubation was measured in an auto gamma scintillation spectrometer (Hewlett-Packard Co., Palo Alto, CA). The muscles were then dried at $60^{\circ} \mathrm{C}$ for at least $6 \mathrm{~h}$ and weighed; the dry weight was preferred to wet because preliminary experiments showed that, despite a reasonably close correlation, the former eliminates considerable individual variability. Where possible, the experiment was performed using the paired technique, in which the two muscles from the same animal were compared. The uptake was expressed as percent of total $\left.{ }^{125} \mathrm{I}\right] \mathrm{T}_{3}$ of $\mathrm{T}_{4}$ per milligram dry weight. The nonspecific uptake 
was determined by adding $10 \mu \mathrm{g}$ unlabeled $\mathrm{T}_{3}$ to the incubation buffer, as previously described (10). The specific uptake component was evaluated as the difference between the total uptake and the nonspecific uptake. All experiments were in triplicate or quadruplicate, and the results are expressed as mean \pm SD of at least three separate experiments. Statistical analysis was performed, where appropriate, using Student's $t$ test for paired data; otherwise, the unpaired $t$ test was used.

\section{Results}

The time course of $T_{3}$ uptake in rat soleus muscle under basal conditions was compared with the uptake from medium in which sodium was replaced by lithium. The results presented in Fig. 1 show that the curves diverge after $15 \mathrm{~min}$, the effect of sodium depletion being to decrease the total uptake by 30\% at $60 \mathrm{~min}$. Note that the muscles were preincubated for 120 min before the addition of labeled $\mathrm{T}_{3}$ (see Discussion). It was shown previously that $T_{3}$ uptake due to the specific or saturable component of uptake approaches equilibrium after $60 \mathrm{~min}$ incubation (10). Furthermore, the amount of decrease in total $T_{3}$ uptake observed after incubation with a saturating level of $T_{3}(10)$ was the same as that seen in present experiments when sodium was replaced by lithium. The results in Table I show that sodium replacement by either lithium or choline signifcantly decreased $\mathrm{T}_{3}$ uptake $(P<0.001)$ and the effect of the two cations did not differ statistically from each other. The addition of excess $\mathrm{T}_{3}$ to the $\mathrm{Na}^{+}$-depleted buffer containing lithium produced no further decrease in $T_{3}$ uptake, indicating that sodium deprivation affected only the specific $T_{3}$ uptake component.

Table I also presents data on the uptake of labeled $T_{4}$ by soleus muscle in basal and sodium-depleted buffer. In contrast with the results obtained with $T_{3}, T_{4}$ uptake was not affected by sodium replacement with either lithium or choline, in keeping with the previously recognized absence of a specific $T_{4}$ uptake component in this tissue (10).

The decrease in $T_{3}$ uptake induced by sodium depletion was proportional to the concentration of sodium in the buffer as shown in Fig. 2. The role of sodium entry on $T_{3}$ uptake in the muscle was investigated further by the use of $10 \mu \mathrm{M}$ monensin, an ionophore that greatly increases the entry of the cation in skeletal muscle (16) through the $\mathrm{Na}^{+}$channel or the $\mathrm{Na}^{+} / \mathrm{H}^{+}$exchanger $(17,18)$ (see below). In both lithium- and

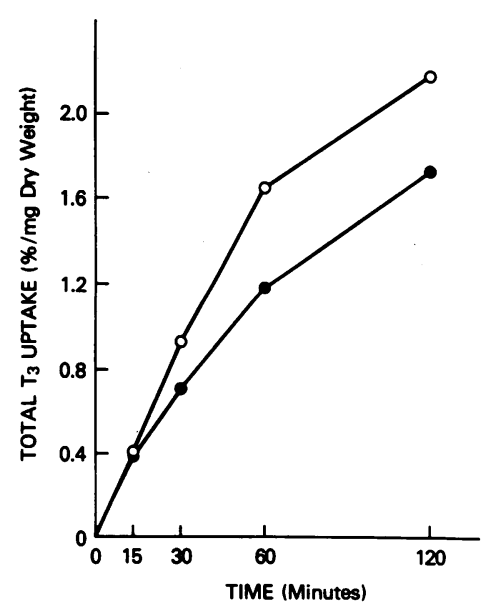

Figure 1. The time course of $\left[{ }^{125} \mathrm{I}\right] \mathrm{T}_{3}$ uptake in the presence of normal ( 140 $\mathrm{mM},-\infty-)$ or low (5 $\mathrm{mM}$, - - ) extracellular $\mathrm{Na}^{+}$. Soleus muscles were preincubated for $120 \mathrm{~min}$ in $\mathrm{KRB}$ buffer at $37^{\circ} \mathrm{C}$, $\mathrm{pH}$ 7.4 and then incubated for the indicated times after adding $50 \mathrm{pM}\left[{ }^{125} \mathrm{I}\right] \mathrm{T}_{3}$. In low sodium buffer, the cation was replaced by equimolar concentrations of lithium. Muscles were incubated in triplicate using the paired technique. The results of one of four such experiments are shown.
Table I. Effect of Sodium Deprivation on Thyroid Hormone Uptake

\begin{tabular}{|c|c|c|c|}
\hline & $\begin{array}{l}\text { Uptake per milligram } \\
\text { dry weight* }\end{array}$ & Change & $P^{*}$ \\
\hline & $\%$ & $\%$ & \\
\hline \multicolumn{4}{|l|}{$\mathrm{T}_{3}$ uptake } \\
\hline Control & $1.63 \pm 0.5$ & - & - \\
\hline $\mathrm{Na}^{+}$replaced by $\mathrm{Li}^{+}$ & $1.19 \pm .09$ & -27 & $<0.001$ \\
\hline Control & $1.55 \pm .1$ & - & - \\
\hline \multicolumn{4}{|l|}{$\mathrm{Na}^{+}$replaced by } \\
\hline choline & $1.20 \pm .14$ & -22 & $<0.001$ \\
\hline Control & $1.67 \pm .09$ & - & - \\
\hline Excess $\mathrm{T}_{3}$ & $1.23 \pm .15$ & -26 & $<0.001$ \\
\hline \multicolumn{4}{|l|}{ Excess $\mathrm{T}_{3}+\mathrm{Na}^{+}$} \\
\hline replaced by $\mathrm{Li}^{+}$ & $1.29 \pm .15$ & -23 & $<0.001$ \\
\hline \multicolumn{4}{|l|}{$T_{4}$ uptake } \\
\hline Control & $0.57 \pm .04$ & - & - \\
\hline $\mathrm{Na}^{+}$replaced by $\mathrm{Li}^{+}$ & $0.66 \pm .1$ & - & NS \\
\hline \multicolumn{4}{|l|}{$\mathrm{Na}^{+}$replaced by } \\
\hline choline & $0.62 \pm .11$ & - & NS \\
\hline
\end{tabular}

* Total uptake by rat soleus muscles at $60 \mathrm{~min}$. Mean $\pm \mathrm{SD}$ of three separate experiments in triplicate.

‡ Compared with control in each group.

choline-containing media, monensin had no effect (Fig. 3), showing that the monensin effect requires the presence of sodium to be expressed.

The possible involvement of the $\mathrm{Na}^{+} / \mathrm{H}^{+}$exchanger in $\mathrm{T}_{3}$ uptake was investigated by using amiloride in conjunction with different cationic buffers. Lithium ion, unlike choline, is able to substitute for sodium in the exchange with intracellular $\mathrm{H}^{+}(17,19)$. Addition of $1 \mathrm{mM}$ amiloride to the normal incubation buffer containing $140 \mathrm{mM} \mathrm{Na}{ }^{+}$had no effect on $\mathrm{T}_{3}$ uptake either in the presence of monensin (Table II) or its absence (data not shown). This was not unexpected since in

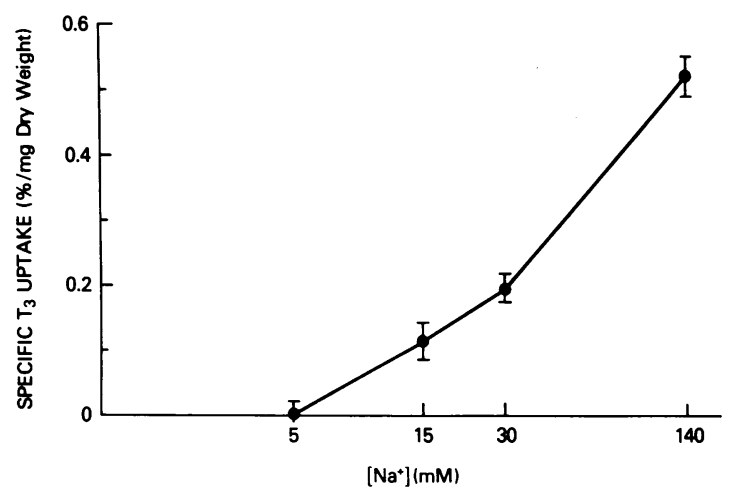

Figure 2. Specific $\mathrm{T}_{3}$ uptake as a function of extracellular sodium.

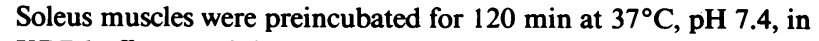
KRB buffer containing different amounts of sodium and then incubated $60 \mathrm{~min}$ with $50 \mathrm{pM}\left[{ }^{125} \mathrm{I}\right] \mathrm{T}_{3}$. Lithium replaced sodium to maintain osmolarity. The specific uptake was obtained by subtracting the nonspecific uptake (the $\mathrm{T}_{3}$ uptake in presence of $10 \mu \mathrm{M}$ unlabeled $T_{3}$ ) from the total uptake. The values are the mean $\pm S D$ of triplicate determinations in three different experiments using the paired technique. 


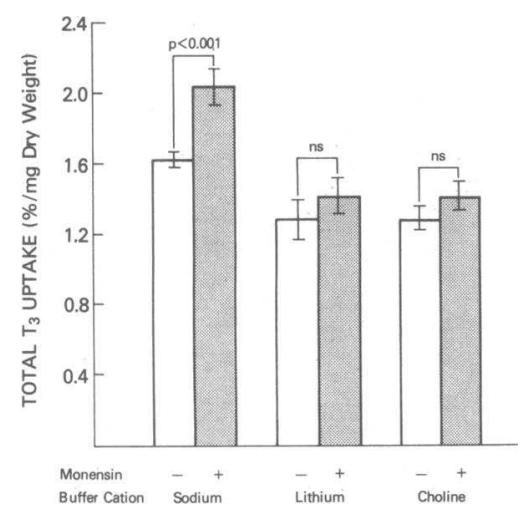
are the mean \pm SD of triplicate determinations in three different experiments.

many systems a sodium concentration as low as $50 \mathrm{mM}$ inhibits the binding of this drug to the $\mathrm{Na}^{+} / \mathrm{H}^{+}$exchanger (20, $21)$. When amiloride was added to the choline-containing buffer, it also did not alter the depressed $\mathrm{T}_{3}$ uptake (Fig. 4). When sodium was replaced by lithium, however, amiloride restored $T_{3}$ uptake to normal. This suggests an involvement of the $\mathrm{Na}^{+} / \mathrm{H}^{+}$exchange system in $\mathrm{T}_{3}$ uptake since both lithium and amiloride, unlike choline, are known to interact with the $\mathrm{Na}^{+} / \mathrm{H}^{+}$exchanger $(17,21)$ and, further, amiloride antagonizes, in skeletal muscle, the lithium effect on intracellular $\mathrm{H}^{+}$ extrusion (17).

Since increased $T_{3}$ entry seemed to be associated with increased $\mathrm{Na}^{+}$entry, and since an increased intracellular $\mathrm{Na}^{+}$ would be expected to activate the $\mathrm{Na}^{+} / \mathrm{K}^{+}$ATPase, the possible role of this pump in $T_{3}$ uptake was investigated. The specific inhibitor ouabain, $1 \mathrm{mM}$, which was shown to block the $\mathrm{Na}^{+} / \mathrm{K}^{+}$ATPase activity in myocytes $(16,22)$, was used and the results are shown in Table III. The mean total $\mathrm{T}_{3}$ uptake was not reduced significantly, but the mean specific $T_{3}$ uptake was reduced $58 \%(P<0.01)$, indicating an involvement of the sodium pump in the process of specific $T_{3}$ uptake in rat skeletal muscle.

\section{Discussion}

In the present study we investigated the relation between sodium movement across the plasma membrane and thyroid

Table II. Effect of Monensin on $T_{3}$ Uptake

\begin{tabular}{lllll}
\hline Additions & $n^{*}$ & $\mathrm{~T}_{3}$ uptake & Change & $P$ \\
\hline & & $\%$ & $\%$ & \\
None & 5 & $1.37 \pm 0.2$ & - & - \\
Monensin & & $1.73 \pm 0.2$ & +27 & $<0.001^{\S}$ \\
Monensin + amiloride & 3 & $1.69 \pm 0.4$ & +23 & $\mathrm{NS}^{\prime \prime}$ \\
& & & & \\
\hline
\end{tabular}

The concentration of monensin and amiloride were $10 \mu \mathrm{M}$ and 1

$\mathrm{mM}$, respectively.

* No. of experiments.

* Percent of total $\mathrm{T}_{3}$ per milligram dry weight.

$\checkmark$ Vs. no addition.

"Vs. monensin alone.

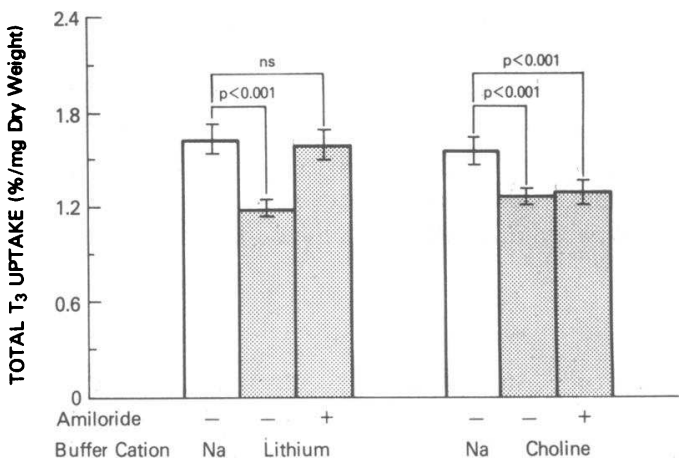

Figure 4. The effect of amiloride on $\mathrm{T}_{3}$ uptake in the presence of low sodium buffer. Soleus muscles were preincubated for $120 \mathrm{~min}$ at $37^{\circ} \mathrm{C}, \mathrm{pH} 7.4$, and then incubated $60 \mathrm{~min}$ with $\left[{ }^{125} \mathrm{I}\right] \mathrm{T}_{3}$ in $\mathrm{KRB}$ buffer in which lithium or choline was substituted for sodium. Amiloride, $1 \mathrm{mM}$, was present, where appropriate, during both preincubation and incubation. The values are the mean \pm SD of triplicate determinations in three different experiments using the paired technique.

hormone uptake in rat skeletal muscle, a tissue in which our previous studies demonstrated a specific component of $T_{3}$ uptake that was saturable and energy as well as temperature dependent (10). In contrast, $T_{4}$ uptake was shown to be insensitive to these factors and there was no evidence for a specific process involved in its entry into muscle (10). Holm et al. (5) and Krenning et al. (6) already pointed out that thyroid hormone uptake in erythrocytes and hepatocytes was sensitive to pretreatment with ouabain. Based on this finding they suggested the importance of a sodium gradient across the plasma membrane; Krenning suggested also a transport of thyroid hormones analogous to the transport of other amino acids.

The present study shows that $T_{3}$ uptake into muscle is partly dependent on extracellular sodium, whereas sodium concentration does not appear to influence $T_{4}$ uptake, confirming a major difference between $T_{3}$ and $T_{4}$ entry. The sodium-sensitive component of $T_{3}$ uptake corresponds to the specific portion of the uptake since the effect of $\mathrm{Na}^{+}$deprivation and of a saturating amount of $T_{3}$ were not additive (Table I). A direct effect of low extracellular sodium on $T_{3}$ uptake is supported by the close correlation between the decrease in specific uptake and the decreasing amount of sodium in the medium (Fig. 2).

The effect of sodium deprivation on $T_{3}$ uptake requires time to become evident; despite a 120 -min preincubation, the effect of sodium replacement by lithium on $\mathrm{T}_{3}$ uptake was seen only after $15-30 \mathrm{~min}$ of incubation. This lag time is similar to that required to see the effect of excess unlabeled $T_{3}(10)$ and is

Table III. Effect of Ouabain on $\dot{T}_{3}$ Uptake

\begin{tabular}{lllll}
\hline & Minus ouabain & $\begin{array}{l}\text { Plus ouabain } \\
(1 \mathrm{mM})\end{array}$ & Change & $P$ \\
\hline & & & $\%$ & \\
Total uptake* & $1.88 \pm 0.33$ & $1.63 \pm 0.29$ & -13 & \multicolumn{1}{l}{ NS } \\
Specific uptake* & $0.41 \pm 0.14$ & $0.17 \pm 0.08$ & -58 & $<0.01$
\end{tabular}

* Petcent of total radioactivity per milligram diry weight. Mean \pm SD of eight separate experiments in triplicate. 
most likely explained by the time required for diffusion of $\mathrm{T}_{3}$ into the intact muscle, as well as the low uptake and the variability between muscles.

Whereas the requirement of extracellular sodium for specific $T_{3}$ uptake seems evident, the mechanism involved is less clear. A role of sodium entry and accumulation in muscle cells in the uptake of $T_{3}$ is indicated by the effect of monensin. This ionophore is an electroneutral, fully reversible, and symmetric $\mathrm{Na}^{+} / \mathrm{H}^{+}$exchanger (21) that is able to increase sodium entry into muscle (16). In the present study monensin increased $T_{3}$ uptake by $27 \%$ at a concentration similar to that used by Rosic et al. (16) to increase by $100 \%$ the sodium uptake into muscle cells. Moreover, when sodium in the medium was replaced by either lithium or choline, the effect of monensin on $\mathrm{T}_{3}$ uptake disappeared, showing that this effect requires sodium to become evident and does not represent a nonspecific change in membrane permeability.

In mouse soleus muscle, under almost the same experimental conditions used in the present study, Aickin et al. (23) showed that the steady state internal $\mathrm{pH}\left(\mathrm{pH}_{\mathrm{i}}\right)$ is maintained mainly by the $\mathrm{Na}^{+} / \mathrm{H}^{+}$exchange system. They also pointed out that a progressive reduction of external sodium causes a significant slowing of $\mathrm{pH}_{\mathrm{i}}$ recovery after acidification, and complete removal of sodium almost stops $\mathrm{pH}_{\mathrm{i}}$ recovery. These findings were confirmed by Vigne et al. (17) in chick skeletal muscle cells, and it was shown that an inward $\mathrm{Na}^{+}$gradient causes intracellular alkalinization and an outward $\mathrm{Na}^{+}$gradient, acidification. These observations raise the question whether the monensin effect on $\mathrm{T}_{3}$ uptake, and $\mathrm{T}_{3}$ uptake itself, are related to sodium entry through the $\mathrm{Na}^{+} / \mathrm{H}^{+}$exchange system or to a change in $\mathrm{pH}_{\mathrm{i}}$ subsequent to a change in $\mathrm{Na}^{+}$gradient.

A direct measurement of $\mathrm{pH}_{\mathrm{i}}$ variations is a subject for another study using a muscle cell system more suitable than intact soleus muscle; however, we investigated the possible involvement of the $\mathrm{Na}^{+} / \mathrm{H}^{+}$exchanger by using amiloride. This diuretic drug is the classical inhibitor of the $\mathrm{Na}^{+} / \mathrm{H}^{+}$exchange system: its action is to block the $\mathrm{Na}^{+}$-dependent $\mathrm{H}^{+}$ efflux from cells in a large number of tissues, including skeletal muscle (16-21). Unfortunately, $\mathrm{Na}^{+}$and amiloride compete for the external transport site of the $\mathrm{Na}^{+} / \mathrm{H}^{+}$pump and the Michaelis constant for $\mathrm{Na}^{+}$is quite low $(<50 \mathrm{mM})$. Therefore, in the presence of a physiological $\mathrm{Na}^{+}$concentration (140 $\mathrm{mM}$ ), amiloride is not effective as an inhibitor (20). As we expected, amiloride had no effect on $\mathrm{T}_{3}$ uptake in the presence of a normal sodium concentration, nor was it able to block the monensin effect, but it was useful as a negative control for nonspecific effects (for a review see reference 20).

In the presence of low extracellular sodium plus lithium, amiloride was able to restore $T_{3}$ uptake to normal. This effect confirms the possibility of an involvement of the $\mathrm{Na}^{+} / \mathrm{H}^{+}$exchange system since both lithium and amiloride interact with this exchanger in soleus muscle (23) and amiloride is known to reverse lithium effects at that level $(17,21)$. That the amiloride effect on $\mathrm{T}_{3}$ uptake may involve the $\mathrm{Na}^{+} / \mathrm{H}^{+}$pump is also indirectly confirmed by the lack of an effect of the drug when sodium was replaced by choline, a cation unable to interact with the pump (17). From this last experiment it becomes evident also that the amiloride effect is not additive to $\mathrm{Na}^{+}$ deprivation in decreasing $T_{3}$ uptake. It is of interest to note that amiloride also interferes with $\mathrm{pH}_{\mathrm{i}}$ recovery after acidification in soleus muscle (23). However, the exact mechanism of the amiloride effect on $T_{3}$ uptake in the presence of lithium is not completely clarified in terms of ion movement, due to the limitations of amiloride use as inhibitor and the complexity of the $\mathrm{Na}^{+} / \mathrm{H}^{+}$system (19).

Whatever mechanism of sodium entry may be involved, an increasing intracellular $\mathrm{Na}^{+}$concentration activates the $\mathrm{Na}^{+} / \mathrm{K}^{+}$ATPase that, therefore, could participate in $\mathrm{T}_{3}$ uptake. Our results suggest that activation of the sodium pump is in some way related to $T_{3}$ entry into muscle since ouabain reduced the specific uptake by $\sim 60 \%$. However, this inhibitory effect was not complete, suggesting that activation of $\mathrm{Na}^{+} / \mathrm{K}^{+}$ATPase may play a secondary role when compared with sodium entry.

In conclusion, this study showed that $T_{3}$ uptake in rat skeletal muscle is partly sodium dependent and that the sodium related $\mathrm{T}_{3}$ uptake closely corresponds to the specific component of this uptake. $T_{4}$ uptake was shown not to be affected by sodium in accord with previous results indicating that passive diffusion is the major pathway of $\mathrm{T}_{4}$ entry into muscle cells (10). The presence of a sodium-dependent process closely connected to specific $T_{3}$ uptake is of particular interest in skeletal muscle since in this tissue the $T_{3}$ associated with the nucleus is exclusively derived from the plasma (11), emphasizing the possible role of the cell membrane in regulating intracellular availability of the hormone.

\section{References}

1. Parl, F., L. Korcek, J. S. Siegel, and M. Tabachnick. 1977. Uptake of triiodothyronine and thyroxine by isolated rabbit adipocytes. FEBS (Fed. Eur. Biochem. Soc.) Lett. 83:145-147.

2. Krenning, E., R. Docter, H. Bernard, T. Visser, and G. Hennemann. 1978. Active transport of triiodothyronine $\left(\mathrm{T}_{3}\right)$ into isolated rat liver cells. FEBS (Fed. Eur. Biochem. Soc.) Lett. 91:113-116.

3. Eckel, J., G. S. Rao, M. L. Rao, and H. Breuer. 1979. Uptake of L-triiodothyronine by isolated rat liver cells. Biochem. J. 182:473-491.

4. Holm, A. C., K. J. Wono, N. B. Pliam, E. C. Jorgensen, and I. D. Goldfine. 1980. Uptake of L-triiodothyronine into human cultured lymphocytes. Acta Endocrinol 95:350-358.

5. Holm, A. C., and C. Jacquemin. 1979. Membrane transport of L-triiodothyronine by human red cell ghosts. Biochem. Biophys. Res. Commun. 89:1006-1017.

6. Krenning, E., R. Docter, B. Bernard, T. Visser, and G. Henneman. 1981. Characteristics of active transport of thyroid hormone into rat hepatocytes. Biochim. Biophys. Acta 676:314-320.

7. Rao, G. S., M. L. Rao, A. Thilman, and H. D. Quednau. 1981. Study of fluxes at low concentrations of L-triiodothyronine with rat liver cells and their plasma membrane vesicles. Biochem. J. 198:457466.

8. Halpern, J., and P. M. Hinkle. 1982. Evidence for an active step in thyroid hormone transport to nuclei: drug inhibition of $\mathrm{L}^{125} \mathrm{I}$-triiodothyronine binding to nuclear receptor in rat pituitary tumor cells. Endocrinology. 110:1070-1072.

9. Cheng, S. Y. 1983. Characterization of binding and uptake of 3,3',5-triiodo-L-thyronine in cultured mouse fibroblasts. Endocrinology. 112:1754-1763.

10. Pontecorvi, A., and J. Robbins. 1986. Energy-dependent uptake of 3,5,3'-L-triiodothyronine in rat skeletal muscle. Endocrinology. 119:2755-2761.

11. van Doorn, J., D. van der Heide, and F. Roelfsema. 1983. Sources and quantity of 3,5,3'-triiodothyronine in several tissues of the rat. J. Clin. Invest. 72:1778-1792.

12. Guidotti, G., A. Borghetti, and G. Gazzola. 1978. The regulation of amino acid transport in animal cells. Biochim. Biophys. Acta 515:329-366.

13. Kilberg, M. S., E. F. Barber, and M. E. Handlogten. 1985. 
Characteristics and hormonal regulation of amino acid transport system "A" in isolated rat hepatocytes. Curr. Top. Cell. Regul. 25:133163.

14. Sato, K., and H. J. Cahnmann. 1980. Synthesis of $\left[3,5^{125} I\right]-$ triiodothyronine of high specific activity. Anal. Biochem. 102:237242.

15. Cuendet, G. S., E. G. Loten, B. Jeanrenaud, and A. E. Renold. 1976. Decreased basal, noninsulin-stimulated glucose uptake and metabolism by skeletal soleus muscle isolated from obese-hyperglycemic (ob/ob) mice. J. Clin. Invest. 58:1078-1088.

16. Rosic, M. D., M. L. Standaert, and R. J. Pollet. 1985. The mechanism of insulin stimulation of $\mathrm{Na}^{+} / \mathrm{K}^{+}$-ATPase transport activity in muscle. J. Biol. Chem. 260:6206-6212.

17. Vigne, P., C. Frelin, and M. Ladzunski. 1984. The $\mathrm{Na}^{+}$-dependent regulation of internal pH in chick skeletal muscle cells. The role of the $\mathrm{Na}^{+} / \mathrm{H}^{+}$exchange system; and its dependence on internal $\mathrm{pH}$. EMBO (Eur. Mol. Biol. Organ.) J. 3:1865-1870.
18. Benos, D. J. 1982. Amiloride: a molecular probe of sodium transport in tissues and cells. Am. J. Physiol. 242:C131-C145.

19. Aronson, P. S. 1985. Kinetic properties of the plasma membrane $\mathrm{Na}^{+} / \mathrm{H}^{+}$exchanger. Annu. Rev. Physiol. 47:545-560.

20. Mahnensmith, R. L., and P. S. Aronson. 1985. The plasma membrane $\mathrm{Na}^{+} / \mathrm{H}^{+}$exchanger and its role in physiological and pathophysiological processes. Circ. Res. 56:773-788.

21. Frelin, C., P. Vigne, and M. Lazdunski. 1985. The $\mathrm{Na}^{+} / \mathrm{H}^{+}$ exchange system. Properties and role in cell function. In Hormones and Cell Regulation. E. J. Dumont, B. Hamprecht, and J. Nunez, editors. Elsevier Science Publishers B. V., Amsterdam. Vol. 9. 259-268.

22. Williams, J. A., C. D. Withrow, and D. M. Woodbury. 1971. Effects of ouabain and diphenylhydantoin on transmembrane potentials, intracellular electrolytes and cell $\mathrm{pH}$ of rat muscle and livers. $J$. Physiol. (Lond.). 212:101-115.

23. Aickin, C. C., and R. C. Thomas. 1977. An investigation of the ionic mechanism of intracellular $\mathrm{pH}$ regulation in mouse soleus muscle fibres. J. Physiol. (Lond.). 273:295-316. 